\title{
Overlap Of Squamous Cell Carcinoma On A Chronic Discoid Lesion Of Lupus Erythematosous On The Lower Lip Of A Woman
}

\author{
S Shamsadini, A Shamsadini
}

\section{Citation}

S Shamsadini, A Shamsadini. Overlap Of Squamous Cell Carcinoma On A Chronic Discoid Lesion Of Lupus Erythematosous On The Lower Lip Of A Woman. The Internet Journal of Dermatology. 2005 Volume 4 Number 2.

DOI: $\underline{10.5580 / 16 \mathrm{a} 0}$

\begin{abstract}
This is report of a 31 year old woman who is a known case of discoid lupus erythematosus (DLE) with superimposing of squamous cell carcinoma (SCC) on an old lesion of DLE. The underlying discoid lesion has been left off as a chronic ulcer on the lower lip. DLE is the most common form of chronic cutaneous lupus erythematosous. SCC is a malignant neoplasm arising from epithelial keratinocytes of the skin and mucous membranes Half of cases with SCC, are usually overlapped on one or more predisposing factors as an underlying cause such as chronic ulcers, scares, radiation and immunologic disorders. Chronic sun exposing skin such as lower lip can induced DLE in susceptible cases, and transformation of DLE to malignancy of SCC also at the next may be appeared. This is a case report of imposing SCC just above a chronic discoid lupus lesion on lower lip. As we know only 4 similar overlapped cases has been reported until now.
\end{abstract}

\section{INTRODUCTION}

Squamous cell carcinoma (SCC) is a malignant neoplasm arising from epithelial keratinocytes of the skin and mucous membranes [ $\left.{ }_{1}\right]$. In half of the cases with SCC, it is associated with predisposing factors such as chronic ulcers, scares, radiation and immunologic disorders $\left[{ }_{1,2}\right]$. This is report of a 31 years old woman who has been evaluated for 11 years with a diagnosis of discoid lupus erythematosus (DLE) and has found a chronic ulcer just on one of a discoid lesion on her lower lip since 1 year ago. Pathological report of a cut section from a wedge shape incision biopsy confirmed the diagnosis of SCC which has been imposed on discoid lesion. Chronic sun exposure skin and sub-mucous area usually may be affected more in DLE because of remaining chronic scar of DLE and persistence of sun exposed risk factor in these cases, only 18 cases has been reported, but one case has been associated of SCC on discoid lesion of lower lip, as we know, $\left[{ }_{3}, 4,5\right]$ and this is a case report more with overlap of SCC just above on one of chronic old discoid lesion on her lower lip.

\section{CASE REPORT}

A 31 year old house wife a known case of disseminated DLE was examined in a private dermatology clinic with multiple similarly wide spread lesions that has been observed on her face scalp and both hands. Their figurations were three colored as in appearance (Fig 1).

\section{Figure 1}

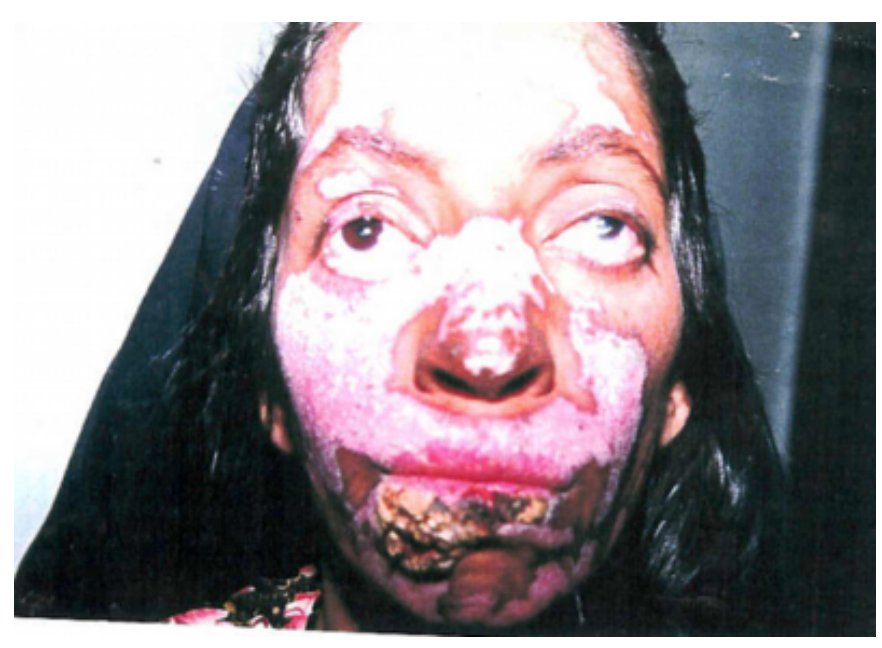

Her new chief complain was appearing of an ulcerated mass with deep fissuring on one of old lesion on lower lip. Hypertrophic ulcer has been appeared just in the center of a discoid rash. 


\section{Figure 2}

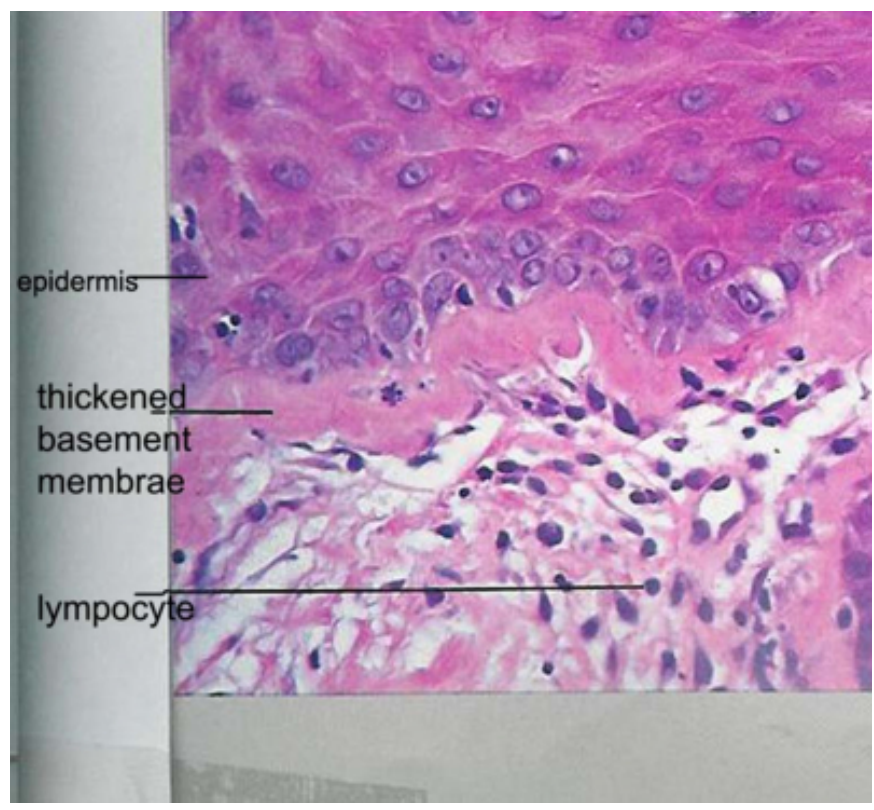

\section{Figure 3}

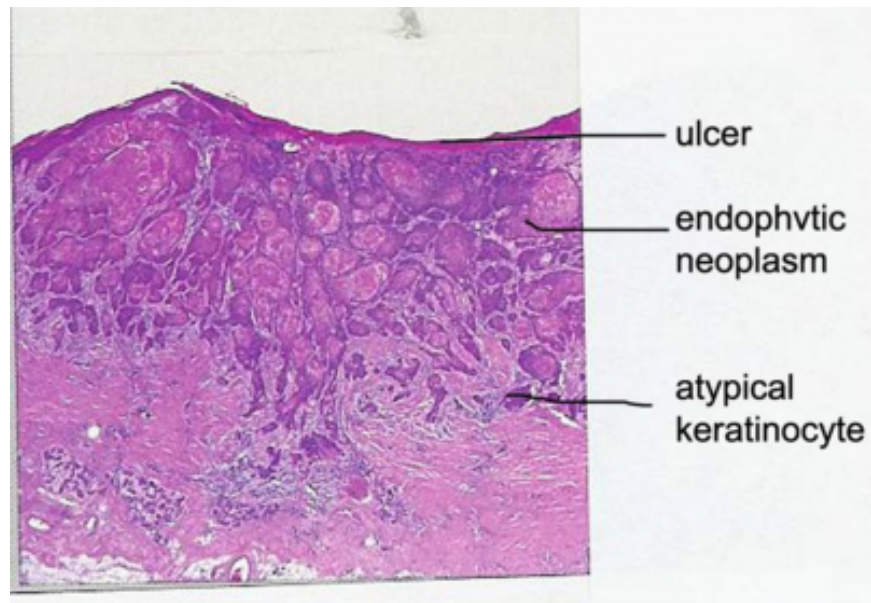

Squamous - Cell Carcinoma of lip

Development of this mass has been growing during last 1 year ago. A pathological study of a cut section from a wedge incision biopsy approved diagnosis of SCC. The remaining examination was normal in this case except ophthalmic examination that a corneal opacity has seen in left eye that has been appeared after invasion of DLE to the ophthalmic cornea. Therapy continued after surgical excision and a de bulking operation of tumor by a safe margin with using hydroxychloroquine $200 \mathrm{mg} /$ day orally and applying locally a thick layer of a potent type of corticosteroid also, the patient has been discharged.

\section{DISCUSSION}

SCC has been reported in a case in 1985 as an overlap in discoid lesions of a patient with late stage of DLE [6]. This is a case report more with overlap of SCC above a late stage of discoid lesion on lower lip. $\left[{ }_{3,4}, 5\right]$. Chronic sun exposure skin and sub-mucous area usually are affected more in discoid lupus but some times disseminated lesions may be appeared also at relatively covered area of the body such as scalp. Association of breast carcinoma and malignant melanoma , and nasal perforation has been reported (case reports) in 3 separated patients with SLE also $\left[{ }_{6,7}, 8\right]$. Diagnosis lesion of DLE in patients with typical late stage is clinically characteristic, but pathological findings and also direct immunoflourescence examination can be obtained to help only in the cases with questionable lesions $\left[{ }_{4,5}, 9\right]$. Our patient has multiple persistent of typical three chrome discoid skin lesions of late stage DLE which squamous cell carcinoma has been overlapped just above a late stage of discoid lesion of lower lip. More evaluation and work up for finding peripheral and visceral metastases. Total excision has been done completely with a safe margin and advising him to taking on antimalarial compound (hydroxychloroquine) tablet orally $200 \mathrm{mg} /$ day and using of steroid ointment locally on other underlying disseminated discoid lesions $\left.{ }_{6}\right]$.

\section{CORRESPONDENCE TO}

Shamsadini MD professor of dermatology Department of Dermatology Kerman University of Medical Sciences, Afzalipoor Hospital Kerman, Iran. Tel (341) 2457272, Fax (341) 2460641 E mail: shamsadini@yahoo.com

\section{References}

1. Heidi A Waldorf Squamous cell carcinoma, by Mark Lebwohl, Warren R. Heymann John Berth-Jones and Ian Coulson .Treatment of skin disease. Mosby W.B Saunders. 2002. p 592.

2. Garrett AB Multiple aquamous cell carcinomas in lesions of discoid lupus Eerythematosus. 1: Cutis. 1985 Oct; 36(4): 313-4, 316 PMID: 4064754.

3. Voigtlander,V\&Boonen.H. Squamous cell carcinoma of the lower lip in discoid lupus erythematosus associated with hereditary deficiency of complement 2. Z Hautkr. 1990 Sep;65(9):836-7 PMID: 2264375

4. Saurat JH, Musette P. Signes cutanes du lupus erythemateux. In : Saurat JH, Grosshans E, Laugier P, lachapelle JM, (eds). Dermatologie et Maladies Sexuellement Transmissibles, 3 ed. Masson, paris, 1999:313-322.

5. Sontheimer RD, lupus Erythematosus. In: Freedberg IN, Eisen AZ, Wolff K, Austen KF, Goldsmith LA, Katz SI,

Fitzpatrick TB, (eds). Dermatology in General Medicine, 5th ed. McGraw-Hill, USA, 1999: pp 1993-2009.

6. Rahman P, Gladman D, Urowitz M. Nasal septum perforation in Systemic Lupus Erythematosus- Time for a 
closer look. J. Rheumathol 1999; 6:1854-1855.

7. Maryanna C Ter poorten, Bruce H Thiers Discoid lupus erythematosous by Mark Lebwohl, Warren R Heymann John Berth-Jones and Ian Coulson. Treatment of skin disease Mosby W.B Saunders. 2002. p 166.

8. R Mascarenhas, O Tellechea, H Oliveira, JP Reis, M Cordeiro, J Migueis. Nasal septum perforation as the presenting sign of lupus eythematosus Dermatology Online Journal 11(2): 12

9. Sulkes A. Naparstek Y The infrequent association of systemic lupus erythamtosus and solid tumors. Sharett Institute of Oncology, Jerusalem, Israel. PMID: 1651808. Lupus, Volume 10, Number 6, June 2001, pp. 394-400(7). 


\section{Author Information}

Sadollah Shamsadini, M.D.

Professor Of Dermatology, Dermatology Kerman, University of Medical Sciences, Afzalipoor Hospital

Ayeh Shamsadini, M.D.

General Practitioner Of Medicine, Dermatology Kerman, University of Medical Sciences, Afzalipoor Hospital 